\title{
Aspects in aesthetic preview in fixed prosthodontic rehabilitation results
}

\author{
Aspecte ale prefigurării estetice a rezultatelor în protezarea fixă
}

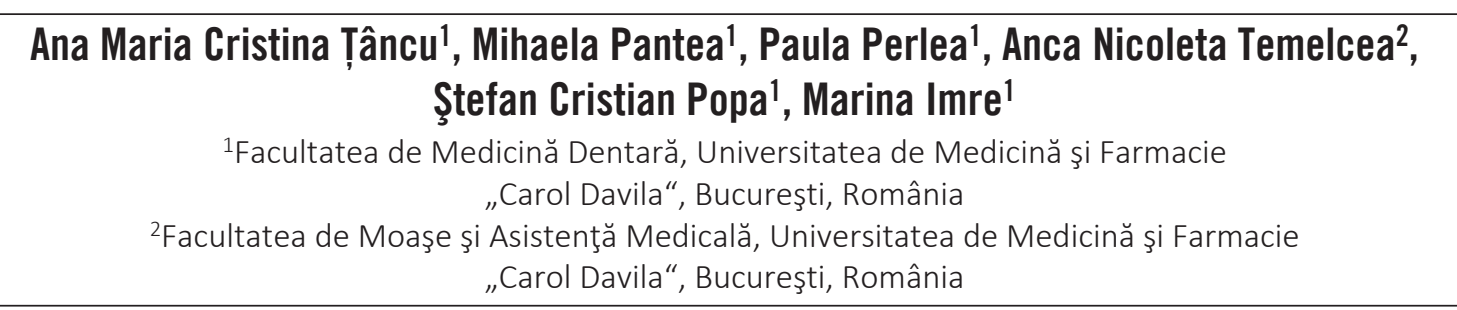

\begin{abstract}
The aesthetic requirements and expectations of patients have increased greatly in the current social context, which has attracted increasing challenges in the clinical work of prosthodontic specialists.

Thus, the predictability of the results of most types of prosthodontic restorations has become absolutely necessary to meet patients' demands, and digital aesthetic prefiguration is a useful and necessary tool. In this context, the paper presents the case of a 55-year-old patient, partially edentulous in the maxillary, rehabilitated by a 13-year-old metal-ceramic bridge. The patient was referred for the reconstruction of the maxillary bridge, which was no longer responding to the aesthetic demands.

After a thorough clinical examination, the treatment plan was established and the old bridge was replaced by classical technique. The result was accepted by the patient, who appreciated it as excellent, aesthetically and functionally. To determine to what extent a digital application can bring an aesthetic value to classical coronary restoration techniques, we have used one of the newest and most advanced techniques of digital aesthetic prefiguration, the Visagism application, which has proposed an ideal look of the teeth, also taking into account the patient's temper-ament, the result of the computer simulation being discussed with the patient.
\end{abstract}

Keywords: aesthetic digital preview, prosthodontic rehabilitation, Visagismile

\section{REZUMAT}

Cerinţele şi aşteptările estetice ale pacienţilor au crescut mult, în contextul social actual, ceea ce a atras după sine provocări tot mai mari în activitatea clinică a specialiştilor proteticieni.

Astfel, predictibilitatea rezultatelor majorităţii tipurilor de restaurări protetice a devenit absolut necesară pentru a veni în întâmpinarea solicitărilor pacienţilor, prefigurarea estetică digitală fiind un instrument util şi necesar.

În acest context, materialul de faţă prezintă cazul unei pacientei, în vârstă de 55 de ani, edentată parţial maxilar, edentaţia maxilară fiind reabilitată protetic printr-o punte metalo-ceramică, cu vechimea de 13 ani. Pacienta s-a prezentat pentru refacerea punţii maxilare, ce nu mai corespundea din punct de vedere estetic. După examinarea clinică minuţioasă s-a stabilit planul de tratament şi s-a procedat la înlocuirea lucrării protetice vechi, prin tehnica clasică. Rezultatul a fost acceptat de către pacientă, care l-a apreciat drept excelent, din punct de vedere estetic şi funcţional.

Pentru a stabili în ce măsură o aplicaţie digitală poate aduce un aport de valoare din punct de vedere estetic tehnicilor clasice de restaurare coronară, am utilizat una din cele mai noi şi avansate tehnici de prefigurare estetică digitală, aplicaţia Visagismile, ce a propus un aspect ideal al dinţilor, ţinând cont şi de temperamentul pacientului, rezultatul simulării computerizate fiind ulterior discutat cu pacienta.

Cuvinte cheie: prefigurare estetică digitală, restaurări protetice, Visagismile

\section{INTRODUCERE}

Stomatologia modernă impune, în condiţiile în care se doreşte obţinerea unui rezultat estetic maxim al tratamentului dentar, crearea unui design al zâmbetului adaptat fiecărui pacient în parte (1). Pa- cienţii sunt din ce în ce mai interesaţi de un rezultat estetic predictibil care să le împlinească complet aşteptările estetice. Tehnicile clasice continuă să existe, dar proteticienii trebuie să se adapteze noii ere. Noile aplicaţii digitale, uşor de folosit, fac pla- 
nul protetic mai facil şi contribuie semnificativ la reuşita tratamentului. $\mathrm{Cu}$ câteva fotografii (puţine), dar corecte, planificarea digitală permite, în câţiva paşi simpli, evaluarea mărimii, formei şi poziţiei dinţilor (2).

Există, în momentul de faţă, diferite aplicaţii, create să facă munca proteticianului mai predictibilă şi cu rezultate estetice mai bune. Unele dintre ele sunt foarte bine cunoscute, aşa cum sunt Digital Smile Design (DSD, Brazilia), Smile Designer Pro (Canada), Digital Smile System (Italy), Dental GPS (Canada), Planmeca Romexis Smile Design (Finlanda) etc. (3).

De multitudinea de sisteme similare disponibile pe piaţă, se diferenţiază aplicaţia Visagismile, ce are la bază conceptul de visagism. Acest nou sistem este creat de echipa DSD (Coachman C. et al.) şi propune cea mai bună potrivire a formei şi mărimii dinţilor pentru a obţine maximum de estetică.

Programul Visagismile foloseşte principiile Digital Smile Design, peste care suprapune şi analiza relaţiilor dintre trăsăturile faciale, temperament şi configuraţia armonioasă a dinţilor pacientului, şi are la bază clasificarea tipurilor de temperamente, descrisă de către Hipocrate şi Gallenus (6), fiind pentru prima dată când temperamentul individului a fost corelat cu forma feţei şi a dinţilor (Fig. 1a, 1b, 1c, 1d) (4).

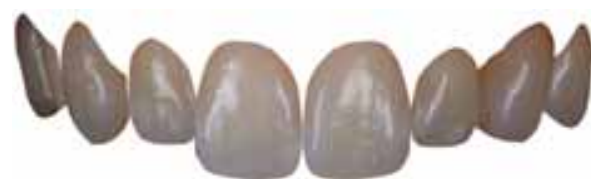

FIGURA 1A. Melancolic/Față ovală/Dinți de formă ovală

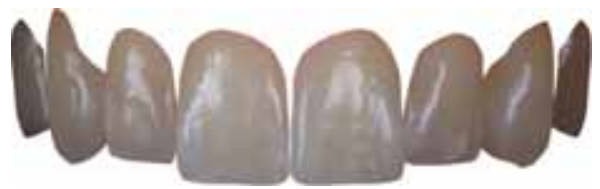

FIGURA 1B. Coleric/Față dreptunghiulară/Dinți de formă dreptunghiulară

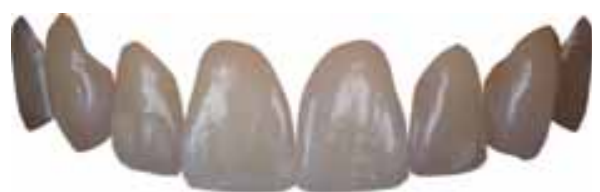

FIGURA 1C. Sanguin/Față angulată/Dinți de formă triunghiulară

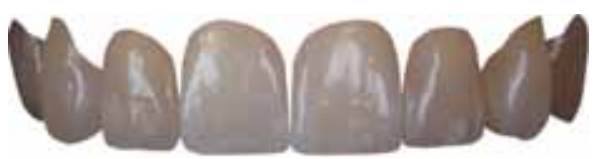

FIGURA 1D. Flegmatic/Față pătrată/Dinți de formă pătrată
Astfel, tipul coleric/puternic este determinat, exploziv, pasional, cu calităţi de lider, tipul sanguin/dinamic este vioi, vesel, optimist, extrovertit, expansiv, comunicativ şi plin de viaţă, tipul melancolic/senzitiv este organizat, puţin comunicativ, perfecţionist, rezervat, timid, închis în sine, iar tipul flegmatic/liniştit este diplomat, pacifist, mistic, spiritual, discret, tenace şi meticulos. Fiecărui tip temperamental îi corespunde o anumită formă a feţei şi o anumită formă a dinţilor.

Derivat din cuvântul francez Visage, care înseamnă faţă, conceptul de visagism a fost explicat şi dezvoltat de către artistul Philip Hallawell şi preluat ulterior de echipa Coachman. A fost dezvoltat în ultimii 8 ani şi validat de un număr mare de cazuri clinice rezolvate $\mathrm{cu}$ ajutorul acestei aplicaţii (7).

$\mathrm{Cu}$ ajutorul conceptului de visagism, medicii stomatologi pot crea un zâmbet care să îmbine aspectul fizic al pacientului cu personalitatea şi dorinţele acestuia. Una dintre cele mai importante provocări este de a identifica aceste trăsături de personalitate şi dorinţe cu ajutorul cărora să se stabilească forma dinţilor în armonie psiho-dento-facială.

Conceptul de visagism este destul de puţin dezvoltat în literatura de specialitate (8), astfel că am considerat oportună compararea rezultatelor - foarte bune şi apreciate de către pacientă - unei protezări fixe realizate prin metoda clasică cu rezultatele estetice propuse de către aplicaţia Visagismile, pentru a putea stabili dacă această aplicaţie răspunde mai bine exigenţelor estetice ale pacientei, deoarece ţine cont şi de trăsăturile de personalitate ale acesteia.

\section{MATERIAL ŞI METODĂ}

O pacientă în vârstă de 55 ani, cu un status general de sănătate bun, s-a prezentat în clinica noastră pentru tratament protetic. După ce pacienta a semnat consimţământul informat (prin care ne-a dat şi acordul, în mod explicit, să utilizăm fotografiile pentru realizarea acestui material), a fost iniţiată procedura evaluării diagnostice, atât din punct de vedere al examenului clinic, cât şi din punct de vedere al examinărilor paraclinice imagistice (OPG şi fotografii documentare) (Fig. 2). Pacienta era protezată, la momentul prezentării, cu o punte metaloceramică la maxilar, cu un aspect estetic necores- 


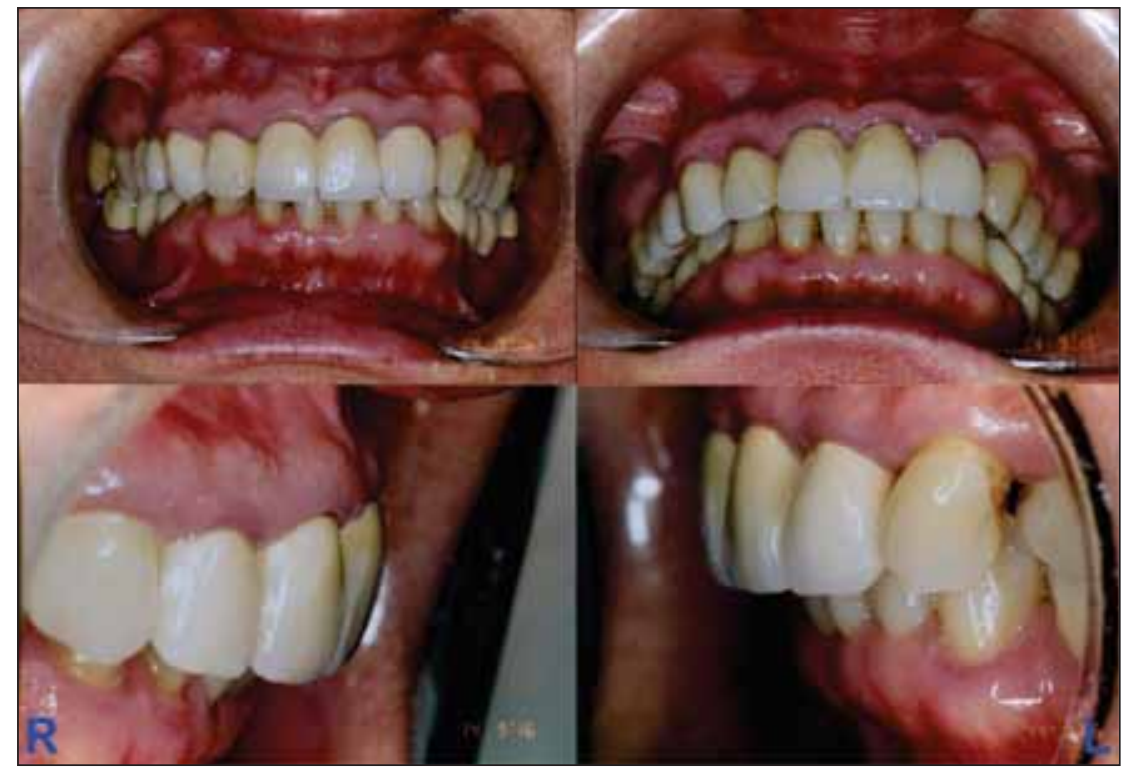

FIGURA 2. Aspectul estetic inițial al pacientei S.M.

punzător, pacienta dorind înlocuirea acesteia din motive estetice. Au fost realizate fotografii din norma frontală în zâmbet maxim şi cu vizibilitate a dinţilor. Pacienta şi-a exprimat cerinţele estetice: o culoare mai deschisă şi mai luminoasă a noii lucrări protetice, în armonie cu dinţii restanţi maxilari şi mandibulari, iar, în final, un zâmbet mai frumos.

Coroborând toate aceste informaţii, s-a procedat la alcătuirea planului de tratament, care a impus, printre alte manevre terapeutice, şi ablaţia punţii metalo-ceramice preexistente.

S-a decis, din mai multe considerente, utilizarea unei tehnici clasice de protezare. S-au amprentat preparaţiile maxilare, prin tehnica sandwich, cu un silicon de condensare de consistenţă chitoasă, împreună cu unul de consistenţă fluidă, obţinându-se o imagine negativă de fineţe a câmpului protetic, ceea ce a permis obţinerea unui model de lucru care a reprodus fidel situaţia clinică, reducând la minimum riscurile de a compromite realizarea unei lucrări fixe metalo-ceramice de calitate.

Culoarea s-a ales utilizând cheia de culori. În laborator, au fost transmise şi alte cerinţe pentru forma viitoarelor coroane. Astfel, s-a cerut o formă diferită a feţei vestibulare a coroanelor, mai puţin accentuate în plan sagital, ce se încadrează mai bine în profilul pacientei.

De asemenea, i s-a propus pacientei modificarea aspectului caninului superior de pe partea stângă (23), pentru a îmbunătăţi rezultatul protezării şi al zâmbetului. În acest scop, 23 a fost preparat la ni- velul feţei vestibulare, printr-o procedură minimum invazivă, pentru o fațetă. Amprentarea pentru faţetă s-a realizat odată cu amprenta pentru punte.

Proba punţii şi cea a faţetei s-au realizat simultan, pacienta putându-şi exprima opinia atât din punct de vedere estetic, cât şi funcţional. Aceasta a fost total de acord cu rezultatul final şi cu aspectul estetic al lucrării protetice, conform cu dorinţele exprimate.

La pacienţii cu exigenţe estetice ridicate, pe lângă abordarea clasică, este necesară o analiză suplimentară, ce ne poate fi oferită de utilizarea unor aplicaţii dedicate, specializate. De aceea, s-a abordat acest caz şi cu ajutorul tehnologiei digitale, folosind programul Visagismile, pentru a vedea dacă utilizarea acestuia (care ţine cont de personalitatea pacientului) ar fi putut duce la un rezultat diferit, precum şi modalitatea în care acesta este apreciat de către pacientă. Am utilizat acest sistem la finalul tratamentului nostru, realizat prin tehnica clasică. Protocolul de lucru a fost următorul:

- În primul timp, s-au realizat 2 fotografii ale pacientei, una din normă frontală, cu zâmbet larg şi vizibilitate maximă a dinţilor, şi una cu maxilarul superior cu buzele retractate.

- În timpul doi, s-a încărcat fotografia de faţă în aplicaţie şi am plasat-o în spatele ramei faciale. S-a realizat calibrarea manuală (mai fidelă decât cea automată), astfel încât cele 2 linii verticale să treacă prin mijlocul pupilelor, linia orizontală să coincidă cu linia bipupilară, iar linia centrală verticală să coincidă cu mediana feţei. 


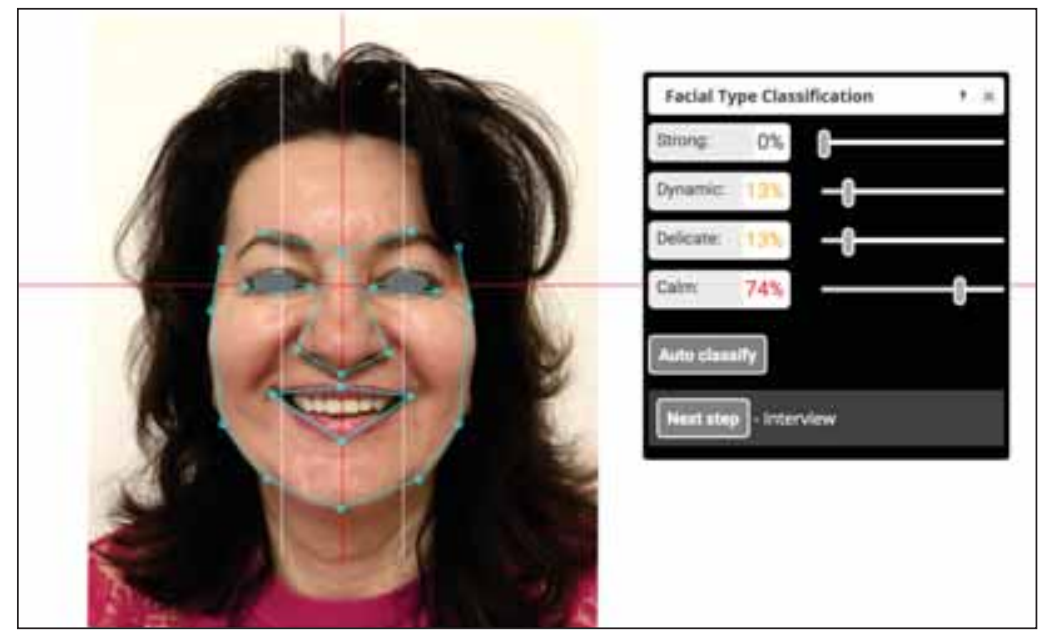

FIGURA 3. Harta facială a pacientei S.M.

S-a obţinut astfel harta facială, care a fost utilizată pentru a stabili tiparul facial. Aspectul feței este determinat de conturul facial, ochi, nas, sprâncene şi de gură. Aceste trăsături faciale sunt selectate utilizând puncte şi linii. Fiecare hartă facială este constituită din 27 puncte. Programul calculează o medie a trăsăturilor în funcţie de cele 4 tipuri de temperament. Folosind parametri statistici şi comparând media cu harta facială trasată, aplicaţia defineşte automat, rapid şi precis tipurile de feţe în procente.

\section{REZULTATE ŞI DISCUŢII}

În urma analizei făcute de către program, a rezultat o hartă facială a pacientei (Fig. 3), hartă ce cuprinde proporţia dintre expresiile feței (puternică, dinamică, senzitivă şi calmă), pacienta noastră fiind $74 \%$ calmă şi, în proporţie egală, $13 \%$ dinamică şi delicată.

Al doilea timp pentru a determina forma optimă a dinţilor a fost reprezentat de completarea unui chestionar (similar unui test psihologic foarte simplu), care cuprinde 4 întrebări şi care este special conceput pentru a stabili tipul personalităţii unui pacient. Tipul personalităţii este automat interpretat de aplicaţie, în funcţie de răspunsurile primite. Combinaţiile de forme ale dinţilor adaptate caracteristicilor individuale ale pacienţilor propuse de sistem sunt: puternic (dreptunghiular), dinamic (triunghiular), senzitiv (oval), calm (pătrat).

Pacienta noastră a răspuns chestionarului şi, ulterior, programul a realizat ceea ce se numeşte sumarul analizei (Analysis Sumary), în care a combi- nat informaţiile din harta facială şi chestionar. În cazul pacientei noastre, rezultatele analizei au recomandat - atât în cazul hărţii faciale, cât şi al testului psihologic - încadrarea pacientei ca fiind calmă (74\%, respectiv 34\%), celelalte tipuri având procente mult mai mici. Programul a propus un design al dinţilor, în funcţie de toate informaţiile introduse până în acest moment. Acest design poate fi folosit ca model pentru planul de tratament.

Astfel, pentru pacienta noastră aplicaţia a recomandat o formă pătrată a IC, cu C ascuţiţi şi uşor înclinaţi palatinal. De asemenea, s-a recomandat plasarea dinţilor frontali maxilari cu axele lor verticale drepte, cu prezenta simetriei verticale, cu conexiunea liniilor rebordului gingival drepte, ca şi conexiunea ambrazurilor. Incisivii centrali trebuie să fie mediu dominanţi.

Rezultatul obţinut de către program a fost prezentat pacientei, aşa cum este indicat în cazul tuturor pacienţilor, acesta fiind unul dintre avantajele utilizării programului, iar pacienta a putut să îşi exprime părerea cu privire la diversele aspecte estetice rezultate, ce pot fi modificate/personalizate în program. Aspectul dinţilor frontali maxilari, sugerat de către program, este prezentat în Fig. 4.

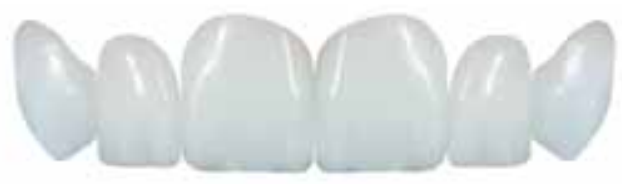

FIGURA 4. Aspectul dinților frontali maxilari propuşi de către program

O comparaţie între aspectul zâmbetului propus de aplicaţie (stânga) şi zâmbetul obţinut în urma 


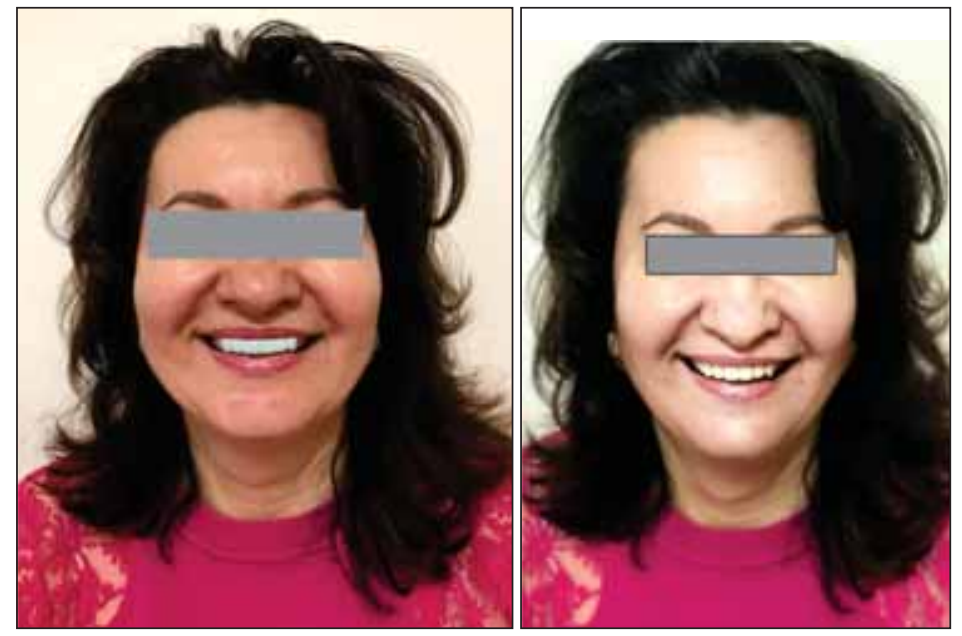

FIGURA 5. Comparație între zâmbetul pacientei prefigurat de aplicația Visagismile (stânga) şi zâmbetul obținut la finalul tratamentului prin metoda clasică

protezării prin tehnica clasică este prezentată în Fig. 5.

Pacienta, mulţumită de protezarea clasică, a analizat rezultatul utilizării programului şi a avut sugestii pentru îmbunătăţirea rezultatului în vederea obţinerii unui aspect estetic perfect.

\section{CONCLUZII}

Aspectele estetice sunt subiective, iar realizarea lucrărilor protetice fixe şi comunicarea cu pacientul sunt dificile mai ales la pacienţii cu exigenţe estetice crescute. De aceea, introducerea programelor de previzualizare estetică a rezultatelor poate contribui la o acceptabilitate mai mare a tratamentului din partea pacienţilor.

Programul Visagismile, comparativ cu alte aplicaţii de ultimă generaţie, asigură o previzualizare estetică îmbunătăţită, datorită integrării şi utilizării informaţiilor legate de temperamentul pacientului, lucrarea protetică finală reflectând personalitatea acestuia şi fiind mult mai bine integrată de către pacient.

Forma dinţilor şi aspectului zâmbetului prefigurate de aplicaţia Visagismile sunt extrem de apropiate de realitate, ceea ce se poate constitui într-un argument puternic pentru implementarea acestor tehnici de predictibilitate în practica stomatologică curentă.

\section{Notă}

Toţi autorii au avut contribuţii egale în realizarea acestui articol.

Conflict of interest: none declared Financial support: none declared

\section{BIBLIOGRAFIE}

1. Chu St. A Biometric Approach To Predictable Treatment Of Clinical Crown Discrepancies. Pract Proced Aesthet Dent, 2007; 19:401-409

2. Coachman C., Calamita M. Digital smile design: A tool for treatment planning and communication in esthetic dentistry quintessence of dental technology. Quintessence Dent Technol. 2012; 35:103-11.

3. Cristache C., Totu Eftimie E. CAD-CAM o tehnologie a mileniului III, Editura Didactică şi Pedagogică 2016: 91-97

4. Paolucci B., Calamita M., Coachman C., Gurel G. Shayder A., Halwell P. Visagism: The art of dental composition. Quintecence Dent Technologies, 2012; 35:187-200

5. Halawell P. Visagismo: Harmonia e estetica, Sao Paulo, Senac 2013

6. White J. Temperament in relation to the teeth. Dent Cosmos, 1884; 26:113-120.

7. Iliev G. Personalized Digital Smile Design for Predictable Aesthetic Results, Balk J Dent Med, 2016; 20:172-177

8. Omar D., Duarte C. The application of parameters for comprehensive smile esthetics by digital smile design programs: A review of literature, The Saudi Dental Journal, 2017 